\title{
Clinical negligence costs: taking action to safeguard NHS sustainability
}

\author{
(9) $(\mathcal{\Theta} \Theta$ OPEN ACCESS
}

The NHS cannot afford to divert more and more money to litigation, and we need to tackle the problem at source. Tim Draycott and colleagues set out four principles to reduce avoidable harm

\section{Christopher Wai Hung Yau clinical research fellow ${ }^{1}$, Bertie Leigh solicitor ${ }^{2}$, Elisa Liberati researcher ${ }^{3}$, Daniel Punch communications specialist ${ }^{3}$, Mary Dixon-Woods professor ${ }^{3}$, Tim Draycott professor ${ }^{1}$}

${ }^{1}$ North Bristol NHS Trust Department of Women's Health, Westbury on Trym, UK; ${ }^{2}$ Hempsons Solicitors, London, UK; ${ }^{3}$ THIS Institute, University of Cambridge, Cambridge, UK

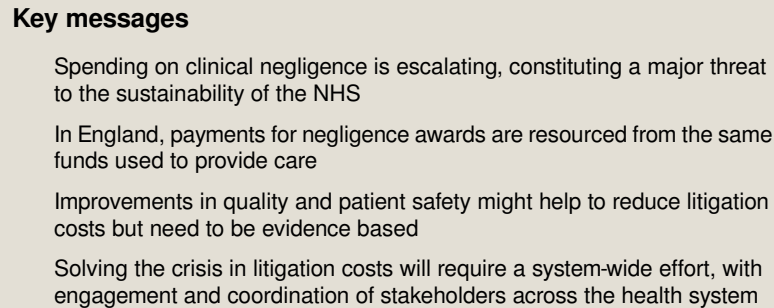

The NHS paid $£ 2.4 \mathrm{bn}(€ 2.8 \mathrm{bn} ; \$ 3.1 \mathrm{bn})$ in clinical negligence claims in 2018-19, according to NHS Resolution (formerly the NHS Litigation Authority). ${ }^{1}$ This sum equates to about $2 \%$ of the entire budget for the NHS in England (roughly £115bn). But even these startling figures do not provide the full picture, since NHS Resolution also has to account for claims likely to be received in the future. Now standing at $£ 83$.4bn, the amount "set aside" for such claims is among the most substantial public sector financial liabilities faced by the UK government, ${ }^{2}$ second only to nuclear decommissioning ( $£ 131 \mathrm{bn})^{3}{ }^{3}$

The Public Accounts Committee has identified that a small number of high value claims, mostly related to maternity care, is a major contributor to these costs. ${ }^{4}$ Maternity accounted for $50 \%$ of the total value of claims received by NHS Resolution in 2018-19, though it represented only $10 \%$ of the total number of claims. ${ }^{1}$ The high cost of these claims arises because injury at birth (including brain injury) can have catastrophic effects over a lifetime.

The patients who are harmed and their families are, of course, those most directly affected by clinical negligence-defined as a breach of the legal duty of care that causes harm. But the strains are felt throughout the system. Every pound spent on clinical negligence is a pound that cannot be spent on care. NHS organisations pay contributions from their own resources into the Clinical Negligence Scheme for Trusts (CNST), a voluntary risk-pooling indemnity scheme operated by NHS Resolution. In what amounts to a "pay as you go" scheme, these contributions are used to make settlements and manage claims. In 2018-19, NHS organisations paid just under $£ 2$ bn into CNST, ${ }^{1}$ but the estimated costs of the liabilities incurred last year was $£ 9 \mathrm{bn}$, over four times the amount collected.

Spending on clinical negligence is forecast to consume $4 \%$ of total trusts' income in 2020, meaning a corresponding loss in the amount available for patient care. ${ }^{4}$ Every baby born in the NHS in England now incurs indemnity costs of $£ 1100 .{ }^{1}$ With roughly 600000 births annually, the NHS pays roughly $£ 12.7 \mathrm{~m}$ a week for the costs of obstetric harm. The rise in costs is widely regarded as unsustainable. ${ }^{6}$ Spending on clinical negligence is increasing much faster than funding for the NHS, tripling in the decade from 2009. ${ }^{7}$ That means that the proportion of scarce NHS resources going to litigation instead of care is worsening. ${ }^{89}$

\section{Reversing the trend}

Clinical negligence costs now represent a major threat to the viability of the NHS. Every incident of avoidable patient harm is deeply distressing for patients and families, has multiple negative effects for healthcare staff and organisations, and consumes resources in investigation and redress. Change is clearly needed.

Some influences on litigation are beyond the scope of control of the health system. For instance, the big jump in the sums awarded for damages in recent years was linked to changes in the personal injury discount rate in March 2017. Although the personal injury discount rate was reset in July 2019 to try to curb the rise in damages, the reset (from $-0.75 \%$ to $-0.25 \%$ ) was less than the initial increase. Furthermore, compensation 
levels are decided by the law, not by the NHS. Tort reform to reduce litigation, while offering some potential, is complex and can be prone to unintended or unwanted consequences. ${ }^{10}$

Other changes relating to litigation can be initiated within the NHS. Some legal costs associated with litigation have been reduced, supported by NHS Resolution's commitment to early admission of liability when appropriate. ${ }^{1}$ Increased use of mediation and other forms of dispute resolution to avert claims going to formal court proceedings are also proving useful.

The best way to control costs, however, is to improve safety so that both patient harm and subsequent litigation are reduced. Improving safety in health systems overall is likely to reduce the level of avoidable harm and thus decrease litigation ${ }^{11-13}$ : the recently published NHS patient safety strategy suggested potential to reduce claims provision by around $£ 750 \mathrm{~m}$ a year by 2025, for example. The Public Accounts Committee's 2017 report accordingly recommended that urgent and coordinated action be taken to reduce patient harm, especially in maternity care. ${ }^{4}$ In seeking to make the necessary improvement, however, a major challenge is that of spending effort and resources wisely. ${ }^{14}$ Ill considered, poorly designed, and badly coordinated drives for "improvement" may interfere with clarity of purpose as well as causing distraction, adding to reporting burdens, and creating resentment without delivering real benefits for patients or the NHS. ${ }^{15}$

We propose four foundational principles for safer care: dealing with structural problems, a real commitment to learning, learning from high performance, and facilitating system-wide improvements.

\section{Invest in staffing and infrastructure}

The major structural challenges faced by the NHS are clearly implicated in safety. They include understaffing across most areas of the health service, with large numbers of vacancies (100 000 in England alone, including more than 41000 nursing vacancies). ${ }^{16}$ Other problems include the poor state of buildings, lack of proper equipment, and challenges in information technology. These problems directly affect safety with additional pervasive effects on workplace morale, ability to provide compassionate and safe care, and burnout. ${ }^{17} 18$

\section{Really commit to learning}

A key principle of ethical healthcare systems is a commitment to learning and improvement. ${ }^{1920}$ Though this commitment has been repeatedly recommended for almost two decades, ${ }^{2021}$ and was reaffirmed by the NHS Resolution 2018-19 annual report, it has been so poorly heeded that some suggest the NHS is an organisation without a memory. ${ }^{22}$ The problem lies not with the principle but with its implementation.

At policy level, one barrier to creating a learning system lies in failure to align the financial (and reputational) incentives across the system. This can leave services exposed to conflicting or competing priorities, demands, and rewards. ${ }^{15}$ More broadly, performance management and incentive schemes, ${ }^{23-25}$ unless carefully designed, encourage a compliance based culture (known colloquially as "box ticking") that risks thwarting an ethos of learning ${ }^{26}$ and undermining professional motivation. ${ }^{27}$

A shift to a more learning centred NHS will need to focus on how organisations and professionals can develop the underlying competencies, conditions, and contexts that enable improvement. These range from practical issues such as data availability and analytical skills through to capabilities and skills in leadership. ${ }^{28}$ Some of the changes proposed in the NHS patient safety strategy, including the new safety learning system to replace the current reporting system, are likely to help. Moving more fully in this direction will require sustained attention from all levels of leadership, including organisational leaders and the healthcare professions.

A commitment to learning means commitment to more, and better, evaluation of improvement efforts. For instance, over 30 programmes or initiatives to improve the safety of intrapartum care were implemented in the UK during 2008-18, but few were rigorously evaluated. Similarly, many of the large scale-and largely successful—programmes for infection prevention and control have gone unstudied. ${ }^{29}$ As a result, the learning associated with these resource intensive campaigns and initiatives has been squandered: the evidence of what works, what doesn't, and why has remained weak and fragmented, challenging those who wish to replicate successful interventions at scale. $^{3031}$

\section{Learn from high performance}

Effective learning in health systems requires learning from success $^{3233}$ not just failure. ${ }^{34}$ The many influences on poor outcomes have been identified in multiple national reports, including confidential inquiries, public inquiries, and other investigations such as those conducted as part of the assessment of negligence claims. These factors almost always include failure to recognise problems or to escalate them appropriately, inadequate leadership, problems with service capacity, and poor communication and teamwork. An evidence base on the characteristics of struggling units is now also emerging and has identified problems such as poor organisational culture, absence of a cohesive mission, experience of system shocks such as organisational scandals or leadership turnover, and dysfunctional external relationships. ${ }^{35}$ But repeated discovery of the same challenges risks lapsing into "admiring the problem" unless action is taken. ${ }^{28}$

The growing "Safety 2" movement urges greater emphasis on learning from what goes right in exceptionally highly performing settings. ${ }^{336-38} \mathrm{New}$ approaches seek to identify and explain what allows certain groups or organisations to maintain good outcomes even though they seem to operate under similar conditions to those that underperform. Sometimes the learning from this so called positive deviance is about particular systems or practices that seem to be most successful in delivering care in an efficient, effective, and patient centred way. Positive deviance can offer highly practical templates for local implementation, helping to control risks more efficiently and effectively. The studies on how to optimise processes "from door to balloon" for patients in need of cardiac catheterisation, for example, showed that careful design of workflows and role clarity can deliver real improvements in outcomes. ${ }^{39}$

Sometimes the learning is broader, identifying the features of high performing organisations that are important for improvement such as creating supportive cultures, building appropriate infrastructures, embedding systems for education and training, and leadership from board members. ${ }^{40}$ Evidence is emerging that purposeful intervention can shift organisational culture, ${ }^{41}$ meaning that system leaders can take clear actions to create the cultures and systems needed to reduce avoidable harm.

Of particular value are accounts of the particular sets of conditions that units or organisations need for continuous improvements. ${ }^{32}$ For instance, one English maternity unit has observed a decrease in litigation spending, ${ }^{42}$ coinciding with improvements in a range of clinical outcomes. ${ }^{434}$ Ethnographic 
analysis of this maternity unit identified the importance of individual technical proficiency, excellent multidisciplinary training, team level competence, high quality coordination, use of multiple forms of data and intelligence about safety and quality, a highly intentional approach to safety and improvement, and constant reinforcement of norms of standards of behaviour. ${ }^{32}$ Now that it is becoming clear what good looks like, we need to focus on replicating these features. Here again, evidence is beginning to emerge but requires further development. ${ }^{45}$

\section{Enable and support system-wide safety improvements}

Many processes, systems, and behaviours relevant to safety can and should be changed at local level. Traditionally, this is where much of the effort of quality improvement has been targeted, encouraged by methods such as plan-do-study-act cycles. However, the focus on local rather than system-wide improvement means that interventions and solutions are sometimes left to local innovation when they should be standardised, or at a minimum harmonised, across the NHS. ${ }^{46}$ An important role exists for a mechanism that can facilitate coordinated, system-wide safety improvements (eg, design of everyday equipment and practices), ${ }^{47}$ sharing of evidence based solutions, learning communities, and co-production across multiple stakeholders, including patients. Well evaluated examples of good collaborative approaches to improving safety that combine high quality data, cooperation across organisations, and use of positive deviance to identify best practices are now appearing. ${ }^{489}$ It will be increasingly important to understand safety as a collective endeavour best achieved by working at scale while recognising the role and value of localisation at unit level.

\section{Conclusions}

The clinical litigation crisis poses a real and perhaps not widely recognised threat to the sustainability of the NHS - many clinicians, for example, are unaware of negligence claims in their own hospital. ${ }^{50}$ The four principles we have identified are supported by evidence, but, as in other countries, the benefits have been missed as a result of poor implementation. ${ }^{51}$ It is an unacceptable irony that the money used to pay for clinical negligence could be invested in providing safe and high quality care. With so much at stake, not least for patients and families, avoidable harm must be reduced. What needs to be done is now clear.

Contributors and sources: BL has handled over 3000 cases of clinical negligence over 40 years and lectures on patient safety. CWHY is an obstetrics and gynaecology registrar. His $\mathrm{PhD}$ explored the use of a system based approach to improve maternity care and tackle the increasing litigation costs in obstetrics. TD is a professor in obstetrics and is vice president of the Royal College of Obstetricians and Gynaecologists. TD is also a senior maternity adviser to NHS Resolution. MDW is the Health Foundation professor of healthcare improvement studies and has studied and reported widely on patient safety. EGL is a researcher with a background in psychology and a specialist interest in maternity safety. DP is a communications specialist with a particular interest in distilling complex topics into informative content. This article arose from discussions about the rising costs of clinical negligence and how best safety might be improved to address this challenge and benefit patients. CWHY drafted the original manuscript. BL, EL, DP, MDW, and TD critically reviewed, revised, and approved the final version. TD is the guarantor.

Competing interests: We have read and understood BMJ policy on declaration of interests and declare the following interests: TD is employed by NHS Resolution as a senior maternity adviser and is a trustee of the PROMPT Maternity Foundation, a UK based charity that undertakes research and provides multiprofessional training. TD is partially funded by the PROMPT Maternity Foundation on a secondment basis from North Bristol NHS Trust. CWHY has previously been partially funded by the PROMPT Maternity Foundation. BL provides legal advice to doctors and hospitals. MDW and EL are research collaborators of TD. DP, EL, and MDW are supported by the Health Foundation's grant to the University of Cambridge for The Healthcare Improvement Studies (THIS) Institute. MDW is a National Institute for Health Research (NIHR) senior investigator (NF-SI-0617-10026).

Provenance and peer review: Not commissioned; externally peer reviewed.

1 NHS Resolution. Annual report and accounts 2018/2019. 2019. https://assets.publishing service.gov.uk/government/uploads/system/uploads/attachment data/file/824345/NHS Resolution Annual Report_and accounts print.pd

2 Office for National Statistics. Wider measures of public sector debt: December 2018. https://www.ons.gov.uk/economy/governmentpublicsectorandtaxes/publicsectorfinance/ articles/widermeasuresofpublicsectornetdebt/december2018

3 Nuclear Decommissioning Authority. Nuclear provision: the cost of cleaning up Britain's historical nuclear sites. 2019. https://www.gov.uk/government/publications/nuclearprovision-explaining-the-cost-of-cleaning-up-britains-nuclear-legacy/nuclear-provisionexplaining-the-cost-of-cleaning-up-britains-nuclear-legacy

4 House of Commons Committee of Public Accounts. Managing the costs of clinical negligence in hospital trusts. Fifth report of session 2017-19 (HC 397). https://publications. parliament.uk/pa/cm201719/cmselect/cmpubacc/397/397.pdf

5 Magro M. Five years of cerebral palsy claims: a thematic review of NHS Resolution data. 2017. https://resolution.nhs.uk/wp-content/uploads/2017/09/Five-years-of-cerebral-palsyclaims A-thematic-review-of-NHS-Resolution-data.pdf

6 Dyer $\mathrm{C}$. Government considers legal reforms to resolve high cost of clinical negligence claims. BMJ 2019;364:11362. 10.1136/bmj.11362 30910905

7 National Health Service Litigation Authority. Report and Accounts 2009 (HC 576). 2009. https://assets.publishing.service.gov.uk/government/uploads/system/uploads/attachment data/file/248285/0576.pdf

8 National Audit Office. Managing the costs of clinical negligence in trusts. 2017. https:// www.nao.org.uk/wp-content/uploads/2017/09/Managing-the-costs-of-clinical-negligencein-trusts.pdf

9 lacobucci G. NHS to get funding boost of $3.4 \%$ a year over next five years. BMJ 2018:361:k2682. 10.1136/bmi.k2682 29914981

10 Viscusi W. Medical malpractice reform: what works and what doesn't. Denver Law Review 2019;96:775-92.

11 Black BS, Wagner AR, Zabinski Z. The association between patient safety indicators and medical malpractice risk: Evidence from Florida and Texas. Am J Health Econ 2017;3:109-39. 10.1162/AJHE_a_00069.

12 Yang Q, Zhang C, Hines K, Calder LA. Improved hospital safety performance and reduced medicolegal risk: an ecological study using 2 Canadian databases. CMAJ Open 2018:6:E561-6. 10.9778/cmajo.20180077 30459173

13 Greenberg MD, Haviland AM, Ashwood JS, Main R. Is better patient safety associated with less malpractice activity? Evidence from California. RAND, 2010. https://www.rand. org/content/dam/rand/pubs/technical_reports/2010/RAND_TR824.pdf

14 Dixon-Woods M. How to improve healthcare improvement. BMJ 2019;367:15514. 10.1136/bmj. .1551431575526

15 Dixon-Woods M, Baker R, Charles K, etal . Culture and behaviour in the English National Health Service: overview of lessons from a large multimethod study. BMJ Qual Saf 2014;23:106-15. 10.1136/bmjqs-2013-001947 24019507

16 Buchan J, Charlesworth A, Gershlick B, Seccombe I. A critical moment: NHS staffing trends, retention and attrition. Health Foundation, 2019.

17 Aiken LH, Sermeus W, Van den Heede K, etal . Patient safety, satisfaction, and quality of hospital care: cross sectional surveys of nurses and patients in 12 countries in Europe and the United States. BMJ 2012;344:e1717. 10.1136/bmj.e1717 22434089

18 Bourne T, Shah H, Falconieri N, etal . Burnout, well-being and defensive medical practice among obstetricians and gynaecologists in the UK: cross-sectional survey study. BMJ Open 2019;9:e030968. 10.1136/bmjopen-2019-030968. 31767585

19 Aveling EL, Parker M, Dixon-Woods M. What is the role of individual accountability in patient safety? A multi-site ethnographic study. Sociol Health IIIn 2016;38:216-32. 10.1111/1467-9566.12370 26537016

20 National Advisory Group on the Safety of Patients in England. A promise to learn: a commitment to act. Improving the safety of patients in England. 2013. https://assets. publishing.service.gov.uk/government/uploads/system/uploads/attachment_data/file/ 226703/Berwick Reportpdf

21 Department of Health. An organisation with a memory. Report of an expert group on learning from adverse events in the NHS chaired by the chief medical officer. 2000. https: //webarchive.nationalarchives.gov.uk/20130105144251/http://www.dh.gov.uk/prod_ consum_dh/groups/dh_digitalassets/@dh/@en/documents/digitalasset/dh_4065086.pdf

22 Sujan M. An organisation without a memory: a qualitative study of hospital staff perceptions on reporting and organisational learning for patient safety. Reliab Eng Syst Saf 2015:144:45-52. 10.1016/j.ress.2015.07.011

23 Himmelstein DU, Ariely D, Woolhandler S. Pay-for-performance: toxic to quality? Insights from behavioral economics. Int $J$ Health Serv 2014;44:203-14. 10.2190/HS.44.2.a 24919299

24 Woolhandler S, Ariely D, Himmelstein DU. Why pay for performance may be incompatible with quality improvement. BMJ 2012;345:e5015. 10.1136/bmj.e5015 22893567

25 Checkland K, McDonald R, Harrison S. Ticking boxes and changing the social world: data collection and the new UK general practice contract. Soc Policy Adm 2007:41:693-710. 10.1111/j.1467-9515.2007.00580.x

26 Armstrong N, Brewster L, Tarrant C, etal . Taking the heat or taking the temperature? A qualitative study of a large-scale exercise in seeking to measure for improvement, not blame. Soc Sci Med 2018;198:157-64. 10.1016/..socscimed.2017.12.033 29353103

27 Khullar D, Wolfson D, Casalino LPJJ. Professionalism, performance, and the future of physician incentives. JAMA 2018:320:2419-20. 10.1001/jama.2018.17719 30476944

28 Dixon-Woods M. Harveian oration 2018: improving quality and safety in healthcare. Clin Med (Lond) 2019;19:47-56. 10.7861/clinmedicine.19-1-47 30651245 
29 Holmes A. Infection prevention and control: lessons from acute care in England. Towards a whole health economy approach. Health Foundation, 2015.

30 Walsh JM, Kandamany N, Ni Shuibhne N, Power H, Murphy JF, O'Herlihy C. Neonatal brachial plexus injury: comparison of incidence and antecedents between 2 decades. Am J Obstet Gynecol 2011;204:324.e1-6. 10.1016/j.ajog.2011.01.020 21345417

31 Brocklehurst P, Field D, Greene K, etal. INFANT Collaborative Group. Computerised interpretation of fetal heart rate during labour (INFANT): a randomised controlled trial. Lancet 2017:389:1719-29. 10.1016/S0140-6736(17)30568-8 28341515

32 Liberati EG, Tarrant C, Willars J, etal . How to be a very safe maternity unit: an ethnographic study. Soc Sci Med 2019;223:64-72. 10.1016/j.socscimed.2019.01.035 30710763

33 Lawton R, Taylor N, Clay-Williams R, Braithwaite J. Positive deviance: a different approach to achieving patient safety. BMJ Qual Saf 2014;23:880-3. 10.1136/bmjqs-2014-003115 25049424

34 Dahlin KB, Chuang Y-T, Roulet TJ. Opportunity, motivation, and ability to learn from failures and errors: review, synthesis, and ways to move forward. Acad Management Ann 2018;12:252-77.10.5465/annals.2016.0049.

35 Vaughn VM, Saint S, Krein SL, etal . Characteristics of healthcare organisations struggling to improve quality: results from a systematic review of qualitative studies. BMJ Qual Saf 2019;28:74-84. 10.1136/bmjqs-2017-007573 30045864

36 Hollnagel E, Wears RL, Braithwaite J. From Safety-I to Safety-II: a white paper. Resilient Health Care Network, 2015. https://resilienthealthcare.net/wp-content/uploads/2018/05/ WhitePaperFinal.pdf

37 Braithwaite J, Wears RL, Hollnagel E. Resilient health care: turning patient safety on its head. Int J Qual Health Care 2015;27:418-20. 10.1093/intghc/mzv063 26294709

38 Mannion R, Davies $\mathrm{H}$. Understanding organisational culture for healthcare quality improvement. BMJ 2018;363:k4907. 10.1136/bmj.k4907 30487286

39 Bradley EH, Curry LA, Spatz ES, etal . Hospital strategies for reducing risk-standardized mortality rates in acute myocardial infarction. Ann Intern Med 2012;156:618-26. 10.7326/0003-4819-156-9-201205010-00003 22547471

40 Fulop NJ, Ramsay AIG. How organisations contribute to improving the quality of healthcare. BMJ 2019;365:I1773. 10.1136/bmj.l1773 31048322

41 Curry LA, Brault MA, Linnander EL, etal . Influencing organisational culture to improve hospital performance in care of patients with acute myocardial infarction: a mixed-methods intervention study. BMJ Qual Saf 2018;27:207-17. 10.1136/bmjqs-2017-006989 29101292
42 Draycott T, Sagar R, Hogg S. The role of insurers in maternity safety. Best Pract Res Clin Obstet Gynaecol 2015;29:1126-31. 10.1016/.jbpobgyn.2015.07.002 26323546

43 Draycott $\mathrm{T}$, Sibanda $\mathrm{T}$, Owen $\mathrm{L}$, etal . Does training in obstetric emergencies improve neonatal outcome?BJOG 2006;113:177-82. 10.1111/j.1471-0528.2006.00800.x 16411995 44 Crofts JF, Lenguerrand E, Bentham GL, etal . Prevention of brachial plexus injury-12 years of shoulder dystocia training: an interrupted time-series study. BJOG 2016;123:111-8. 10.1111/1471-0528.13302 25688719

45 Horton TJ, Illingworth JH, Warburton WHP. Overcoming challenges in codifying and replicating complex health care interventions. Health Aff (Millwood) 2018;37:191-7. 10.1377/hlthaff.2017.1161 29401020

46 Dixon-Woods M, Martin GP. Does quality improvement improve quality? Future Hosp $\mathrm{J}$ 2016;3:191-4. 10.7861/futurehosp.3-3-191 31098223

47 Dixon-Woods M, Pronovost PJ. Patient safety and the problem of many hands. BMJ Qual Saf 2016;25:485-8. 10.1136/bmjqs-2016-005232 26912578

48 Share DA, Campbell DA, Birkmeyer N, etal . How a regional collaborative of hospitals and physicians in Michigan cut costs and improved the quality of care. Health Aff (Millwood) 2011;30:636-45. 10.1377/hlthaff.2010.0526 21471484

$49 \mathrm{Vu}$ JV, Collins SD, Seese E, etal . Evidence that a regional surgical collaborative can transform care: surgical site infection prevention practices for colectomy in Michigan. $J$ Am Coll Surg 2018:226:91-9. 10.1016/j.jamcollsurg.2017.10.013 29111416

50 Machin JT, Hardman J, Harrison W, Briggs TWR, Hutton M. Can spinal surgery in England be saved from litigation: a review of 978 clinical negligence claims against the NHS. Eur Spine J 2018;27:2693-9. 10.1007/s00586-018-5739-1 30151803

51 Wears R, Sutcliffe K. Still not safe: patient safety and the middle-managing of American medicine. Oxford University Press, 201910.1093/oso/9780190271268.001.0001.

(C) Author(s) (or their employer(s)) 2019. Re-use permitted under CC BY-NC. No commercial re-use. See rights and permissions. Published by

BMJ.http://creativecommons.org/licenses/by-nc/4.0/This is an Open Access article distributed in accordance with the Creative Commons Attribution Non Commercial (CC BY-NC 4.0) license, which permits others to distribute, remix, adapt, build upon this work non-commercially, and license their derivative works on different terms, provided the original work is properly cited and the use is non-commercial. See: http://creativecommons. org/licenses/by-nc/4.0\%. 